\title{
Evaluation of Knowledge of Medical Students of University of Lomé (Togo) on the Contribution of Prostate Biopsy in the Detection of Prostate Cancer
}

\author{
Tchilabalo Matchonna Kpatcha ${ }^{{ }^{*}}$, Toukilnan Djiwa², Albadia Sidibé3, Edoé Viyomé Sewa ${ }^{4}$, \\ Gnimdou Botcho', Komi Hola Sikpa ${ }^{1}$, Essodina Padja ${ }^{4}$, Sassil Daré5, Mazamaesso Tchaou ${ }^{3}$, \\ Tchin Darré2
}

${ }^{1}$ Department of Urology, University Teaching Hospital of Kara, Kara, Togo

${ }^{2}$ Department of Pathology, University Teaching Hospital of Lomé, Lomé, Togo

${ }^{3}$ Department of Radiology, University of Lomé, Lomé, Togo

${ }^{4}$ Department of Urology, University Teaching Hospital of Lomé, Togo

${ }^{5}$ Department of Surgery, University Teaching Hospital of Lomé, Togo

Email: ^fakpatcha@yahoo.fr, constantdjiwa@gmail.com, albadiasidibe@yahoo.fr, viyomedoe35@yahoo.fr, aristbo@yahoo.fr, docjno@yahoo.fr, padjarodrigue@yahoo.fr, sassildare@yahoo.fr, joseph_tchaou@yahoo.fr, paolodarre@yahoo.fr

How to cite this paper: Kpatcha, T.M., Djiwa, T., Sidibé, A., Sewa, E.V., Botcho, G., Sikpa, K.H., Padja, E., Daré, S., Tchaou, M. and Darré, T. (2021) Evaluation of Knowledge of Medical Students of University of Lomé (Togo) on the Contribution of Prostate Biopsy in the Detection of Prostate Cancer. Open Journal of Urology, 11, 317-325. https://doi.org/10.4236/oju.2021.119030

Received: February 4, 2021

Accepted: September 11, 2021

Published: September 14, 2021

Copyright $\odot 2021$ by author(s) and Scientific Research Publishing Inc. This work is licensed under the Creative Commons Attribution International License (CC BY 4.0).

http://creativecommons.org/licenses/by/4.0/

\begin{abstract}
Background: Prostate cancer is the second leading cause of death from cancer in humans in most developed countries. In Togo, around 59.8\% of prostate cancers are diagnosed at an advanced stage because of the insufficient screening in connection with the recent introduction of prostate biopsy and the late generalization of PSA (prostate specific antigen). Objective: This study aimed to assess the knowledge of students from the Faculty of Health Sciences of the University of Lomé on the contribution of prostate biopsy in the diagnosis of prostate cancer. Results: A total of 1017 students filled out the form, with an overall response rate of $95.3 \%$. The range age of the subjects was 24.5 years, and a sex ratio $(\mathrm{M} / \mathrm{F})$ of 2.51 . The majority of students were license (546, 53.69\%). Five hundred and eighty-one (57.13\%) of the students had not received any training in prostate cancer. Five hundred and eighty-two students (57.23\%) had no knowledge of prostate biopsy. There is a statistically significant link between students' knowledge of the prostate biopsy and age (OR 1, 95\% CI [0.49 - 2.03], $\mathrm{p}=0.0001$ ), sex (OR 1, 95\% CI [0.33 $1.08], \mathrm{p}=0.0003)$, the study cycle (OR $2.5,95 \%$ CI [1.02 - 5.06], $\mathrm{p}=0.0047)$ and the effectiveness of an internship in urology department (OR 1, 95\% CI [0.61 - 1.31], $\mathrm{p}<0.0001)$. Conclusion: Medical students have little knowledge of the place of biopsy in the detection of prostate cancer. Educational efforts
\end{abstract}


should focus on improving their knowledge so that they can make appropriate decisions in the future.

\section{Keywords}

Prostate Cancer, Biopsy, Knowledge, Medical Students, Togo

\section{Introduction}

Prostate cancer is the second leading cause of death from cancer in humans in most developed countries, and the global burden of this disease is increasing [1]. More than half of these prostate cancers are diagnosed before the age of 75 [2]. The constant decrease in specific mortality from prostate cancer observed in recent years in the USA and France through data from cancer registers, partly responds to the interest in individual screening for men aged 50 to 75 with a long life expectancy greater than 10 years [3] [4]. The diagnosis of prostate cancer is established by prostate biopsy and allows a real mapping of the prostate to be carried out [5] [6]. Many prostate cancers are detected based on high plasma levels of prostate specific antigen (PSA $>4 \mathrm{ng} / \mathrm{mL}$ ), a glycoprotein normally expressed by prostate tissue [6]. However, because men without cancer have also been found with high PSA levels, a tissue biopsy is the standard of care to confirm the presence of cancer [7].

In Africa, prostate cancer is first cancer in both the occurrence and the number of deaths [8] [9]. It is also the leading human cancer in Togo, accounting for $74.63 \%$ of urological cancers [10]. In Togo, around $59.8 \%$ of prostate cancers are diagnosed at an advanced stage (Gleason score $>7$ ) [11]. This is probably due to insufficient screening in connection with the recent introduction of prostate biopsy and the late generalization of PSA, but also to the lack of exhaustive registration of cases treated in a liberal environment. Medical students who are future general practitioners play an essential role in health prevention, because they are the first prescribers of PSA. The objective of this study was to assess the knowledge of medical students of the Faculty of Health Sciences at the University of Lomé on the contribution of prostate biopsy in the early detection of prostate cancer.

\section{Methods}

\subsection{Study Plan and Sampling}

A cross-sectional study was carried out among students regularly enrolled in the Faculty of Health Sciences (FSS) of the University of Lomé (UL) in the 2019-2020 school year account. Togo is a country of $56,600 \mathrm{Km}^{2}$, with an estimated population of 7,200,000 located between Ghana in the west and Benin in the east. The total number of students regularly registered with the UL FSS was 1635. The minimum sample size $(n)$ was calculated using the following formula: 


$$
n=t^{2} \times p \times(1-p) / m^{2} .
$$

t. 1.96: value corresponding to the $95 \%$ confidence level.

$p$ : estimated prevalence rate $=0.4$.

$m$ : desired degree of precision $=0.05$.

$n=(1.96)^{2} \times 0.4(1-0.4) /(0.05)^{2}=368.79$.

The minimum sample size $n=368.79$ or 369 students.

We enrolled 1017 of 1635 students, representing $62.2 \%$ of the total FSS student population. It took place from January 1 to March 31, 2020, duration of 3 months.

The selection criteria were the statute of regularly registered students and the agreement to participate in the study.

\subsection{Data Collection}

The data were collected using a self-administered anonymous structured questionnaire, divided into three (03) main parts. The survey questionnaire included an introductory first part detailing the objectives and methodology of the study. The second part sought information on the socio-demographic characteristics of the students, the notion of previous training or courses on prostate cancer and the experience of an internship in a urology department. The third part dealt with their level of knowledge on prostate biopsy. The knowledge was considered bad if the student hadn't any notion on prostate biopsy, intermediate if the conditions of realization were known and good if conditions of realization and signification of the result were known. The socio-demographic section focused on the personal characteristics of the students in the sample, such as age, gender, level of medical education. The section on prostate biopsy included 3 questions concerning the conditions for carrying out this examination. These were questions that subjects should answer with "Yes" or "No". The questionnaire was pre-tested on 50 students, without any particular problem.

\subsection{Data Management and Analysis}

Data was entered twice in Microsoft Excel to reduce data entry errors and then exported to Epi Info version 7 software. A descriptive analysis was carried out with a view to highlighting the characteristics of the different qualitative and quantitative variables. We used percentages for qualitative variables and means with their standard deviations for quantitative variables. The statistical tests used were the Paerson Chi-square test for the qualitative variables and the Student test for the quantitative variables. The significance threshold was set at 0.05 .

\section{Results}

\subsection{Epidemiological Data}

Table 1 shows the sociodemographic characteristics of the participants. The self-administered questionnaire was returned by a total of 1017 students, with an overall response rate of $95.3 \%$. The average age of the subjects was 24.5 years 
Table 1. Socio-demographic characteristics.

\begin{tabular}{|c|c|}
\hline & Value \\
\hline Total & 1017 \\
\hline \multicolumn{2}{|l|}{ Age (years) } \\
\hline 1) Middle age & 24.5 \\
\hline 2) Range & $17-32$ \\
\hline 3) $\leq 25$ & $821 / 1017(80.7 \%)$ \\
\hline 4) $>25$ & $196 / 1017(19.3 \%)$ \\
\hline \multicolumn{2}{|l|}{ Sex } \\
\hline 1) Male & $727 / 1017(71.5 \%)$ \\
\hline 2) Female & $290 / 1017(28.5 \%)$ \\
\hline \multicolumn{2}{|l|}{ Study cycle } \\
\hline 1) Doctorate & $357 / 1017(35.1 \%)$ \\
\hline 2) Master & $114 / 1017(11.2 \%)$ \\
\hline 3) License & $546 / 1017(53.7 \%)$ \\
\hline \multicolumn{2}{|l|}{ Training/courses } \\
\hline 1) Yes & $581 / 1017(57.1 \%)$ \\
\hline 2) No & $436 / 1017(42.9 \%)$ \\
\hline a) $\leq 6$ months & $68 / 436(15.6 \%)$ \\
\hline b) Between 6 months and 1 year & $33 / 436(7.6 \%)$ \\
\hline c) $>1$ year & $335 / 436(76.8 \%)$ \\
\hline \multicolumn{2}{|l|}{ Internship in a urology department } \\
\hline Yes & $886 / 1017(87.1 \%)$ \\
\hline No & $131 / 1017(12.9 \%)$ \\
\hline
\end{tabular}

with extremes of 17 and 32 years. Eight hundred and twenty-one (821) or $80.73 \%$ of the students were 25 years of age or less. These were 727 (71.48\%) male subjects and $290(28.52 \%)$ female subjects, representing a sex ratio (M/F) of 2.51. According to the university course, $357(35.10 \%)$ were in the Doctorate cycle, 114 (11.21\%) in the Master cycle and 546 (53.69\%) in the Bachelor cycle. Five hundred and eighty-one (581) or $57.13 \%$ of the students had received no training or course in prostate cancer. Sixty-eight (68) or 6.69\%, $33(3.24 \%)$ and $335(32.94 \%)$ had received training or a course in prostate cancer, with a delay of less than 6 months respectively, between 6 months and 1 year, and more than a year. Eight hundred and eighty-six (886) or $87.12 \%$ of students had never completed an internship in a urology department.

\subsection{Knowledge of the Prostate Biopsy}

Five hundred and eighty-two (57.23\%) students had no knowledge of the prostate biopsy. These were 510 students, or $93.40 \%$ of those in the Bachelor's cycle. 
For students in the Master and Doctorate cycles, respectively $79(69.29 \%)$ and $320(89.63 \%)$ had knowledge of the prostate biopsy. Ninety-two $(09.05 \%)$ students had previously requested a patient's prostate biopsy. Seventy-two (78.26\%) had requested it in patients with abnormal prostate rectal examination associated with elevated PSA (prostate specific antigen), 15 (16.30\%) with PSA elevation alone and 05 (5.44\%) before only an abnormal digital rectal examination of the prostate. There is a statistically significant link between students' knowledge of the prostate biopsy and age (OR $1,95 \%$ CI $[0.49-2.03]), \mathrm{p}=0.0001)$, gender (OR 1, 95\% CI [0.33 - 1.08], $\mathrm{p}=0.0003$ ), the study cycle (OR 2.5, 95\% CI [1.02 5.06], $\mathrm{p}=0.0047)$ and the effectiveness of an internship in urology department (OR 1, 95\% CI [0.61 - 1.31], $\mathrm{p}<0.0001$ ). On the other hand, there is no statistically significant link between students' knowledge of the prostate biopsy and taking a course or training in prostate cancer (OR 1.72, 95\% CI [0.12 - 2.95], $\mathrm{p}=$ 1.345) (Table 2).

\section{Discussion}

Our study has some limitations like any series based on opinion poll. The sincerity of the answers cannot be verified.

Table 2. Socio-demographic characteristics VS knowledge on prostate biopsy.

\begin{tabular}{|c|c|c|c|c|c|}
\hline \multirow{2}{*}{ Socio-demographic characteristics } & \multicolumn{5}{|c|}{ Univariate analysis (Knowledge of prostate biopsy) } \\
\hline & $\mathrm{n} / \mathrm{N}$ & $\%$ & OR & IC à 95\% & P-value \\
\hline \multicolumn{5}{|l|}{ Sex } & 0.0003 \\
\hline Male & $330 / 727$ & 45.4 & 1 & - & \\
\hline Female & $105 / 290$ & 36.2 & 0.5 & {$[0.33-1.08]$} & \\
\hline \multicolumn{6}{|l|}{ Age } \\
\hline$\leq 21$ years & $48 / 524$ & 9.2 & 1 & - & 0.0001 \\
\hline$>21$ years & $387 / 493$ & 78.5 & 0.86 & {$[0.49-2.03]$} & \\
\hline \multicolumn{6}{|l|}{ Study Cycle } \\
\hline License & $36 / 546$ & 6.6 & 1 & - & 0.0047 \\
\hline Master & $79 / 114$ & 69.3 & 3.4 & {$[1.02-3.72]$} & \\
\hline Doctorat & $320 / 357$ & 89.6 & 2.15 & {$[1.83-5.06]$} & \\
\hline \multicolumn{6}{|c|}{ Follow up on your latest prostate cancer training/course } \\
\hline Less than 6 months & $60 / 68$ & 88.2 & 1 & - & 1.345 \\
\hline Between 6 months and 1 year & $30 / 33$ & 90.9 & 0.33 & {$[0.12-1.95]$} & \\
\hline More than 1 year & $297 / 335$ & 88.7 & 0.68 & {$[0.45-1.22]$} & \\
\hline None & $48 / 581$ & 8.3 & 1.72 & {$[1.31-2.95]$} & \\
\hline \multicolumn{6}{|c|}{ Effectiveness of an internship in urology department } \\
\hline Yes & $120 / 131$ & 91.6 & 1 & - & $<0.0001$ \\
\hline No & $315 / 886$ & 35.6 & 0.72 & {$[0.61-1.31]$} & \\
\hline
\end{tabular}


Prostate cancer is an adenocarcinoma that is most often sporadic ( $80 \%$ of cases), but can be hereditary ( $10 \%$ of cases) or familial (10\% of cases) [12]. Prostate cancer in the initial stage shows intraglandular cancerous lesions or intraepithelial neoplasias that do not reach the prostate capsule [12]. Medical educators must teach students the nuances and uncertainties of detecting prostate cancer, and future physicians will ultimately need to integrate this knowledge into communication with their patients. Our study provides an overview of contemporary knowledge on the detection of prostate cancer in medical students. The PSA test has received negative press in recent years, which is why the controversy surrounding prostate cancer screening continues [1] [2] [3] [4]. Since a reduction in the incidence of the disease through effective primary prevention or the use of pharmacological treatments is not expected, at least in the short term, secondary prevention with PSA test seems to remain the most appropriate [13]. In addition, decisions regarding prostate cancer screening should be based on the preferences of an informed patient. The majority of students $(80.73 \%)$ are 25 years of age or younger. None belonged to the group of subjects at risk of prostate cancer. Indeed prostate cancer is a cancer of the elderly, and screening is recommended in men from 40 years if there is a family history of prostate cancer or breast cancer in a first-time relative degree, and generally from the age of 50 in all other men [5] [6] [7]. We noted a clear male predominance with a sex ratio $(\mathrm{M} / \mathrm{F})$ of 2.51. Given that this is an exclusively male pathology, this explains a pronounced interest in the male gender.

Prostate biopsies allow the histological diagnosis of prostate cancer [14]. They are carried out by a urologist or a radiologist in a patient who presents a clinical suspicion with an abnormality in the rectal or biological touch (PSA $>4 \mathrm{ng} / \mathrm{ml}$ ) [15] [16]. They are performed under ultrasound control with an 18 Gauge needle, on an outpatient basis or in a day hospital, under local, locoregional or general anesthesia [16]. An isolated elevation of the PSA level should not prompt immediately to perform a biopsy, this rate should be checked after a few weeks using the same dosage under standardized conditions including, no ejaculation, digital rectal examination, urethral manipulations or urinary tract infection [17]. A hemostasis check-up is required if a bleeding disorder is suspected. In the absence of clinical or imaging abnormalities (ultrasound or MRI), the 12-sample regimen is recommended [18]. In case of clinical or imaging abnormalities, additional directed biopsies are performed [19]. The indications for a new biopsy are linked to the increase or persistence of a high PSA level, suspect digital rectal examination, and the presence of atypical small acinar proliferation on the first series, the existence of 'a diagnostic doubt on a first series of biopsies [20] The second series must include 4 to 6 additional biopsies, in the anterior apex and the transition zone (anterior fibromuscular stroma) in search of anterior cancer [21]. Many authors have shown in clinical studies that the percentage of cancers detected exclusively by additional transitional zone biopsies is very low [22] [23]. For Bazinet, only $2.9 \%$ of cancers diagnosed by an extensive protocol (combining conventional peripheral biopsies and biopsies of the transition zone) are de- 
tected exclusively by biopsies directed in the transition zone [23]. In practice, guidelines are not often followed; one of the main causes being the lack of knowledge of general practitioners about the recommendations [7]. This observation was made among medical students at the University of Lomé. In fact, the majority of participants $(57.23 \%)$ had no knowledge of the prostate biopsy. There is a statistically significant link between the students' knowledge of the prostate biopsy and the effectiveness of an internship in a urology department (p-value $<0.0001 ; 95 \%$ CI $[0.61-1.31]$ ). It is desirable to continue this supervision in the field of these future physicians, in order to allow them to make informed decisions regarding the non-negligible risks of the prostate biopsy. On the other hand, there is no statistically significant link between students' knowledge of the prostate biopsy and taking a course or training in prostate cancer (p-value $=1.345 ; 95 \%$ CI $[0.12-2.95])$. This suggests a reinforcement of knowledge capacities on the prostatic biopsy of the latter during theoretical courses at the faculty [24] [25].

\section{Conclusion}

Prostate cancer is a common but heterogeneous condition. Confirmation of the diagnosis requires a prostate biopsy. This act involves risks including allergy, hemorrhage, or secondary infection. The patient's information must be prior to the biopsy procedure and delivered in consultation with the doctor indicating the biopsies. Doctors hardly follow these recommendations for lack of knowledge. The same observation was made among medical students at the University of Lomé. It is necessary to strengthen their knowledge of prostate biopsy in order to equip them for informed decision-making in the future.

\section{Conflicts of Interest}

The authors declare no conflicts of interest regarding the publication of this paper.

\section{References}

[1] Bray, F., Ferlay, J., Soerjomataram, I., Siegel, R.L., Torre, L.A. and Jemal, A. (2018) Global Cancer Statistics 2018: GLOBOCAN Estimates of Incidence and Mortality Worldwide for 36 Cancers in 185 Countries. CA: A Cancer Journal for Clinicians, 68, 394-424. https://doi.org/10.3322/caac.21492

[2] Taitt, H.E. (2018) Global Trends and Prostate Cancer: A Review of Incidence, Detection, and Mortality as Influenced by Race, Ethnicity, and Geographic Location. American Journal of Men's Health, 12, 1807-1823. https://doi.org/10.1177\%2F1557988318798279

[3] Wong, M.C., Goggins, W.B., Wang, H.H., Fung, F.D., Leung, C., Wong, S.Y., et al. (2016) Global Incidence and Mortality for Prostate Cancer: Analysis of Temporal Patterns and Trends in 36 Countries. European Urology, 70, 862-874. https://doi.org/10.1016/j.eururo.2016.05.043

[4] Smith-Palmer, J., Takizawa, C. and Valentine, W. (2019) Literature Review of the Burden of Prostate Cancer in Germany, France, the United Kingdom and Canada. 
BMC Urology, 19, Article No. 19. https://doi.org/10.1186/s12894-019-0448-6

[5] Pereira-Azevedo, N.M. and Venderbos, L.D.F. (2018) eHealth and mHealth in Prostate Cancer Detection and Active Surveillance. Translational Andrology and Urology, 7, 170-181. https://doi.org/10.21037/tau.2017.12.22

[6] Stovsky, M., Lee, P., Vourganti, S., Stuhldreher, P., Siroky, M.B., Kipnis, V., et al. (2011) Prostate Specific Antigen/Solvent Interaction Analysis (PSA/SIA): A Preliminary Evaluation of a New Assay Concept for Detecting Prostate Cancer Using Urinary Samples. Urology, 78, 601-605. https://doi.org/10.1016/j.urology.2011.03.071

[7] Cabana, M.D., Rand, C.S., Powe, N.R., Wu, A.W., Wilson, M.H., Abboud, P.A., et al. (1999) Why Don't Physicians Follow Clinical Practice Guidelines? A Framework for Improvement. JAMA, 282, 1458-1465. https://doi.org/10.1001/jama.282.15.1458

[8] Osaghae, S.O. (2020) Update of Guidelines for Management of Prostate Cancer in West Africa 2019: Consensus Working Document. West African Journal of Medicine, 37, 159-172.

[9] Adeloye, D., David, R.A., Aderemi, A.V., Iseolorunkanmi, A., Oyedokun, A., Iweala, E.E.J., et al. (2016) Estimate of the Incidence of Prostate Cancer in Africa: A Systematic Review and Meta-Analysis. PLoS ONE, 11, e0153496. https://doi.org/10.1371/journal.pone.0153496

[10] Darre, T., Kpatcha, T.M., Bagny, A., Maneh, N., Gnandi-Piou, F., Tchangai, B., et al. (2017) Descriptive Epidemiology of Cancers in Togo from 2009 to 2016. Asian Pacific Journal of Cancer Prevention, 18, 3407-3411.

[11] Darré, T., Folligan, K.U., Kpatcha, T.M., Kanassoua, K., Sewa, E., Daré, S., et al. (2017) Evolution of the Histo-Epidemiological Profile of Urological Cancers in Togo. Asian Pacific Journal of Cancer Prevention, 18, 491-494.

[12] Rawla, P. (2019) Epidemiology of Prostate Cancer. World Journal of Oncology, 10, 63-89. https://doi.org/10.14740/wjon1191

[13] Cuzick, J., Thorat, M.A., Andriole, G., Brawley, O.W., Brown, P.H., Culig, Z., Eeles, R.A., Ford, L.G., Freddie, C., et al. (2014) Prevention and Early Detection of Prostate Cancer. The Lancet Oncology, 15, e484-e492. https://doi.org/10.1016/S1470-2045(14)70211-6

[14] Kim, H.-S., Lee, C.-Y., Lim, D.-H., Kim, C.-S. and Baik, S. (2012) The Prostate Cancer Detection Rate on the Second Prostate Biopsy According to Prostate-Specific Antigen Trend. Korean Journal of Urological Oncology, 53, 686-690. https://doi.org/10.4111/kju.2012.53.10.686

[15] Marije Hoogland, A., Kweldam, C.F. and van Leenders, G.J.L.H. (2014) Prognostic Histopathological and Molecular Markers on Prostate Cancer Needle-Biopsies: A Review. BioMed Research International, 2014, Article ID: 341324. https://doi.org/10.1155/2014/341324

[16] Diogo, G.S., Daniel, O.R., Catarina, T., Frederico, T., Luís, O., Manuel, G., et al. (2019) Prostate Biopsy Evolution and the Need for Repeat Biopsy-The Role of Image and New Prostate Cancer Biomarkers. Archivos Espanoles de Urologia, 72, 677-689.

[17] Drost, F.-J.H., Osses, D.F., Nieboer, D., Steyerberg, E.W., Bangma, C.H., Roobol, M.J. and Schoots, I.G. (2019) Cochrane Urology GroupProstate MRI, with or without MRI-Targeted Biopsy, and Systematic Biopsy for Detecting Prostate Cancer. Cochrane Database of Systematic Reviews, No. 4, Article ID: CD012663. https://doi.org/10.1002/14651858.CD012663.pub2 
[18] Liu, L., Tian, Z., Zhang, Z. and Fei, B. (2016) Computer-Aided Detection of Prostate Cancer with MRI: Technology and Applications. Academic Radiology, 23, 1024-1046. https://doi.org/10.1016/j.acra.2016.03.010

[19] Boesen, L., Nørgaard, N., Løgager, V., Balslev, I., Bisbjerg, R., Thestrup, K.-C., et al. (2018) Assessment of the Diagnostic Accuracy of Biparametric Magnetic Resonance Imaging for Prostate Cancer in Biopsy-Naive Men: The Biparametric MRI for Detection of Prostate Cancer (BIDOC) Study. JAMA Network Open, 1, Article ID: e180219. https://doi.org/10.1001/jamanetworkopen.2018.0219

[20] Kim, S.H., Park, B., Joung, J.Y., Chung, J., Seo, H.K., Lee, K.H. and Park, W.S. (2019) Retrospective Study of the Significant Predictive Role of Inflammatory Degree in Initial and Repeat Prostate Biopsy Specimens for Detecting Prostate Cancer. Cancer Research and Treatment, 51, 910-918. https://doi.org/10.4143/crt.2018.314

[21] Jia, Y., Zhu, L.-Y., Xian, Y.-X., Sun, X.-Q., Gao, J.-G., Zhang, X.-H., et al. (2017) Detection Rate of Prostate Cancer Following Biopsy among the Northern Han Chinese Population: A Single-Center Retrospective Study of 1022 Cases. World Journal of Surgical Oncology, 15, Article No. 165. https://doi.org/10.1186/s12957-017-1238-9

[22] Minhaj Siddiqui, M., George, A.K., Rubin, R., Rais-Bahrami, S., Parnes, H.L., Merino, M.J., et al. (2016) Efficiency of Prostate Cancer Diagnosis by MR/Ultrasound Fusion-Guided Biopsy vs Standard Extended-Sextant Biopsy for MR-Visible Lesions. Journal of the National Cancer Institute 108, djw039. https://doi.org/10.1093/jnci/djw039

[23] Bazinet, M., Karakiewicz, P.I., Aprikian, A.G., Trudel, C., Aronson, S., Nachabé, M., et al. (1996) Value of Systematic Transition Zone Biopsies in the Early Detection of Prostate Cancer. Journal of Urology, 155, 605-606. https://doi.org/10.1016/S0022-5347(01)66463-2

[24] Mincey, K., Turner, B.L., Anderson, K., Maurice, S., Neal, R. and White, C. (2017) Prostate Knowledge, Attitudes and Beliefs in Black College Men: A Qualitative Study. Journal of Community Health, 42, 1096-1101. https://doi.org/10.1007/s10900-017-0357-0

[25] Darré, T., Amégbor, K., Kpatcha, M., Tengue, K., Sonhaye, L., Doh, K., et al. (2014) Urologic Cancers in Togo: Histo-Epidemiological Profile of 678 Cases. African Journal of Cancer, 6, 27-31. https://doi.org/10.1007/s12558-013-0296-3 